Article

\title{
Designed Antimicrobial Peptides for Topical Treatment of Antibiotic Resistant Acne Vulgaris
}

\author{
Kathryn W. Woodburn ${ }^{1, *}$, Jesse Jaynes ${ }^{2}$ and L. Edward Clemens ${ }^{1}$ \\ 1 Riptide Bioscience, Inc., 941 Railroad Avenue, Vallejo, CA 94952, USA; eclemens@riptidebio.com \\ 2 Integrative Biosciences, College of Agriculture, Environment and Nutritional Sciences, Tuskegee University, \\ Tuskegee, AL 36088, USA; jjsqrd@bellsouth.net \\ * Correspondence: kathryn.w.woodburn@gmail.com
}

Received: 26 December 2019; Accepted: 9 January 2020; Published: 13 January 2020

check for updates

\begin{abstract}
Acne vulgaris, caused by the Gram-positive bacterium Cutibacterium acnes, is a prevalent dermatologic condition with substantial cutaneous and psychological morbidity. Mild acne is treated with topical antibiotics with more severe inflammatory forms requiring the prolonged use of oral antibiotics, resulting in antimicrobial resistance development. Innovative treatment alternatives, providing complete microbicidal eradication with minimal safety issues and limited susceptibility to microbial resistance, are fervently sought. Designed antimicrobial peptides (dAMPs) are engineered analogs of naturally occurring AMPs that possess a reduced likelihood of developing bacterial resistance. Seven novel dAMP sequences were screened for in vitro bactericidal effectiveness against antibiotic resistant C. acnes clinical isolates. Five peptides (RP444, RP551, RP554, RP556, and RP557) exhibited potent in vitro antibacterial activity. The Therapeutic Index, a measure of specificity for killing multidrug resistant $C$. acnes over mammalian cells, was determined using bioluminescent human keratinocytes. The Therapeutic Index was highest for the disulfide dAMP, RP556, with a value of 130. The lead dAMP candidate RP556, was further evaluated in a multidrug-resistant $C$. acnes intradermal murine infection model. A topical application of $5 \mathrm{mg} / \mathrm{mL}$ RP556 (0.5\%) eliminated infection. If these preclinical results are translated clinically, dAMPs may become a viable topical monotherapy for the treatment of recalcitrant acne infections.
\end{abstract}

Keywords: acne; antimicrobial peptides; bacterial resistance; multidrug resistance; topical treatment

\section{Introduction}

Acne vulgaris is a chronic inflammatory skin disorder affecting more than $80 \%$ of all adolescents and young adults worldwide [1]. The disease can manifest severe social and psychological expressions, including crippling effects on patients' self-esteem and socialization. The pathogenesis of acne is multifactorial and usually implicates follicular colonization with the Gram-positive Cutibacterium acnes (C. acnes; formerly Propionibacterium acnes), resulting in bacterial overgrowth and inflammation. Current acne treatments present side effects such as erythema, scaling, burning, hair bleaching [2], bacterial resistance, and teratogenic effects [3]. Mild forms of acne are often treated with topical antibiotics, with severe inflammatory forms requiring the prolonged use of oral antibiotics resulting in the development and spread of antimicrobial resistance [4]. Many countries report that more than 50\% of $C$. acnes strains are resistant to antibiotics, making them substantially less effective [1].

Monotherapy for the management of acne with currently approved topical antibiotics [5], according to the American Academy of Dermatology "Guidelines of Care for the Management of Acne Vulgaris," is not recommended due to concerns related to the development of antibiotic resistance. Clindamycin is the preferred topical antibiotic; however, its widespread and often permissive use has led to the generation of resistant strains [5]. Topical erythromycin is also used; however, it has 
reduced efficacy in comparison with clindamycin, and C. acnes exhibits resistance to it. Moreover, Staphylococci have generated resistance following treatment of $C$. acnes patients [6]. In an attempt to reduce the development of bacterial resistance, systemic antibiotic treatment is limited to 3 months as recommended by the American Academy of Dermatology [5]. Despite the critical need for new antibiotics with novel modes of action that are active against multidrug resistant (MDR) pathogens, the development of antibacterial agents has drastically declined [7]. Therefore, a monotherapy acne treatment that is highly potent with a reduced likelihood of developing antimicrobial resistance and with anti-inflammatory activity is urgently needed.

Designed antimicrobial peptides (dAMPs) are laboratory synthesized peptides that are rationally designed analogs of naturally occurring AMPs, which provide the first line of defense against invading pathogens in all multicellular organisms [8-10]. dAMPs, also known as host defense peptides, have direct antibiotic activities in addition to modulating immune responses [8]. dAMPs possess an amphipathic $\alpha$-helix or $\beta$-sheet structure and a net positive charge, physicochemical features crucial as the peptides act as antimicrobial agents by electrostatically interacting and selectively perturbing the barrier function of the bacterial membrane. This membrane is rich in anionic phospholipids and negatively charged lipopolysaccharides, in contrast to mammalian cells that are predominantly composed of zwitterionic phospholipids [11]. The remarkable targeting and direct disruption of the bacterial membrane makes bacterial resistance development less likely [8].

\section{Results}

\subsection{Designed Antimicrobial Peptides}

The seven dAMPs evaluated here, whose amino acid sequences are outlined in Figure 1, were carefully tailored to improve upon both natural and synthetic AMP libraries. Iterative evaluations to obtain optimal anti-pathogenic function have found that acceptable activity is attained when the peptide contains an amphipathic region of around 17 contiguous amino acids. To optimize the inhibition of pathogenic activity, while concurrently minimizing eukaryotic toxicity, the hydrophobicity of the non-polar region was maximized by using phenylalanine $(\mathrm{F})$, isoleucine $(\mathrm{I})$, and leucine $(\mathrm{L})$. These conformational changes are coupled, in an effort to maximize the positive charge density of the peptide's polar region, by the incorporation of lysine $(\mathrm{K})$ and or/arginine $(\mathrm{R})$ and C-terminus amidation. The replacement of lysine $(\mathrm{K})$ with the non-natural amino acid, ornithine $(\mathrm{O})$, was made to increase antibacterial activity while also enhancing proteolytic stability [12].

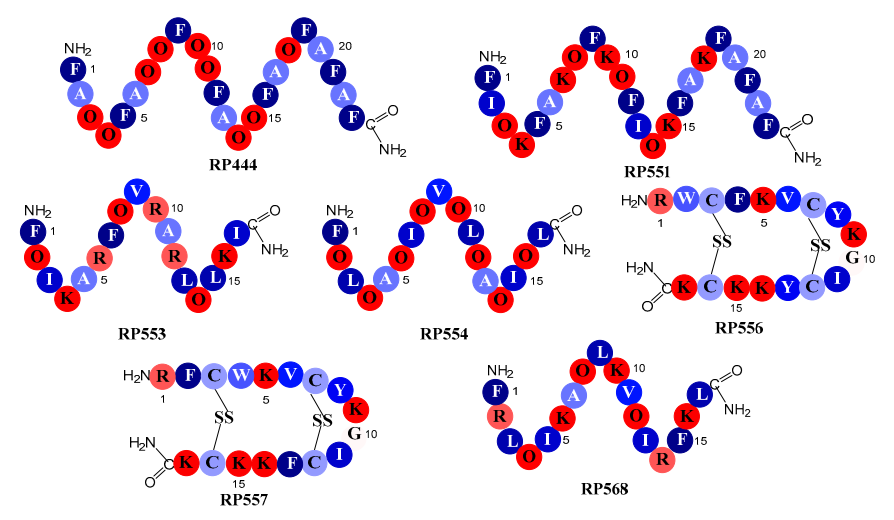

Figure 1. Schematic representation of the designed antimicrobial peptides. Single letter codes of the amino acids are depicted with color coding representing relative hydrophobicity. All hydrophobic amino acids are colored blue while hydrophilic amino acids are red. The number values are normalized and relative hydrophobicities are represented by the number of $\mathrm{kcal} / \mathrm{mole}$ necessary to move an amino acid in an $\alpha$-helix from the aqueous phase to the inside of a lipid bilayer [13]: F, phenylalanine, -3.85 ; L, leucine, -3.36; I, isoleucine, -3.16; Y, tyrosine, -2.66; V, valine, -2.34; W, tryptophan, -1.96 ; A, alanine, -1.56 ; C, cysteine, -1.06 ; $\mathrm{G}$, glycine, $-0.14 ; \mathrm{R}$, arginine, 2.22; $\mathrm{O}$, ornithine, 3.56; and lysine, $\mathrm{K}, 3.85$. 


\subsection{C. acnes In Vitro Antibacterial Activity}

Seven novel dAMP sequences (Figure 1) were screened for their in vitro bactericidal effectiveness; Minimum Inhibitory Concentration (MIC) with dosing range between $0.5 \mu \mathrm{g} / \mathrm{mL}$ and $32 \mu \mathrm{g} / \mathrm{mL}$, against ten $C$. acnes clinical isolates from BEI resources and two C. acnes ATCC reference strains. RP444, RP551, RP554, RP556 and RP557 were the most active peptides against the $C$. acnes bacterial strains, while RP553 showed modest anti-bacterial activity and RP568 exhibited negligible activity over the 0.5-32 $\mu \mathrm{g} / \mathrm{mL}$ concentration range evaluated (Table 1 ). The dAMPs exhibited similar activity against all $C$. acnes isolates evaluated, including antibiotic-resistant $C$. acnes strains (tetracycline, erythromycin and clindamycin).

Table 1. Growth Inhibition of dAMPs (MICs, $\mu \mathrm{g} / \mathrm{mL}$ ) against C. acnes Isolates.

\begin{tabular}{lcccccccccc}
\hline \multirow{2}{*}{ C. acnes } & \multicolumn{3}{c}{ Antibiotic Sensitivity } & \multicolumn{7}{c}{ dAMPs } \\
\cline { 2 - 10 } & Tetra ${ }^{\#}$ & Ery ${ }^{\#}$ & Clind $^{\#}$ & RP444 & RP551 & RP553 & RP554 & RP556 & RP557 & RP568 \\
\hline ATCC6919 & $\mathrm{S}$ & $\mathrm{S}$ & $\mathrm{S}$ & 2 & 2 & 8 & 4 & 4 & 8 & $>32$ \\
ATCC11827 & $\mathrm{S}$ & $\mathrm{S}$ & $\mathrm{S}$ & 8 & $2-4$ & 16 & 8 & 8 & 8 & $>32$ \\
HL007PA1 & $\mathrm{R}$ & $\mathrm{R}$ & $\mathrm{R}$ & 4 & 2 & 16 & 4 & 4 & 8 & $>32$ \\
HL013PA1 & $\mathrm{R}$ & $\mathrm{R}$ & $\mathrm{R}$ & 4 & 2 & 8 & $2-4$ & 2 & 2 & $>32$ \\
HL038PA1 & $\mathrm{R}$ & $\mathrm{R}$ & $\mathrm{R}$ & 4 & 2 & 16 & 8 & 4 & 8 & $>32$ \\
HL043PA1 & $\mathrm{R}$ & $\mathrm{R}$ & $\mathrm{R}$ & 4 & 2 & 16 & 4 & 4 & 8 & $>32$ \\
HL043PA2 & $\mathrm{R}$ & $\mathrm{R}$ & $\mathrm{R}$ & 8 & 2 & 16 & 8 & 4 & 8 & $>32$ \\
HL045PA1 & $\mathrm{R}$ & $\mathrm{R}$ & $\mathrm{R}$ & 4 & 2 & 16 & 4 & 4 & 4 & $>32$ \\
HL053PA1 & $\mathrm{R}$ & $\mathrm{R}$ & $\mathrm{R}$ & 4 & 2 & 16 & 4 & 4 & 4 & $>32$ \\
HL056PA1 & $\mathrm{R}$ & $\mathrm{R}$ & $\mathrm{R}$ & 4 & 2 & 16 & 4 & 2 & 4 & $>32$ \\
HL072PA1 & $\mathrm{R}$ & $\mathrm{R}$ & $\mathrm{R}$ & 8 & $2-4$ & 16 & 8 & 8 & 8 & $>32$ \\
HL082PA2 & $\mathrm{R}$ & $\mathrm{R}$ & $\mathrm{S}$ & 2 & 2 & 16 & 8 & 2 & 2 & $>32$ \\
\hline
\end{tabular}

Antibiotic sensitivity; $\mathrm{S}$, sensitive; R, resistance. ${ }^{\#}$ Antibiotic resistance to clindamycin defined by MIC $\geq 32 \mu \mathrm{g} / \mathrm{mL}$ with resistance to tetracycline (Tetra), MIC $\geq 1.0 \mu \mathrm{g} / \mathrm{mL}$ and erythromycin resistance MIC $\geq 0.5 \mu \mathrm{g} / \mathrm{mL}$ [12]. Data represents the mean of three replicates.

\subsection{Limited Mammalian Cytotoxicity}

The candidate dAMPs, based on physicochemical properties, preferentially destroy bacterial membranes over mammalian membranes. In order to confirm this activity, the time and concentration-dependent effects of dAMPs on human keratinocytes were evaluated (Figure 2). Limited toxicity to mammalian cells was observed after $8 \mathrm{~h}$ of exposure with RP553, RP556 and RP557, all of which showed at least greater than $80 \%$ viability following $8 \mathrm{~h}$ incubation at $256 \mu \mathrm{g} / \mathrm{mL}$, with RP556 exhibiting the least amount of cytotoxicity.

\subsection{High Therapeutic Index}

In evaluating the clinical utility of each of the candidate dAMPs for $C$. acnes treatment, the Therapeutic Index was determined. The Therapeutic Index is defined as the ratio of concentration at which the dAMP is active against the prokaryotic $C$. acnes pathogen without inducing cytotoxic damage to the surrounding mammalian cells. The $\mathrm{EC}_{10}$ and $\mathrm{EC}_{50}$ doses, defined as the concentrations required to kill $10 \%$ and $50 \%$ respectively of human keratinocytes following $8 \mathrm{~h}$ incubation with each of the Riptide dAMPs, are tabulated and graphed in Table 2 and Figure 3, respectively. The larger the Therapeutic Index, the greater the specificity of the dAMP for destroying C. acnes cells. 


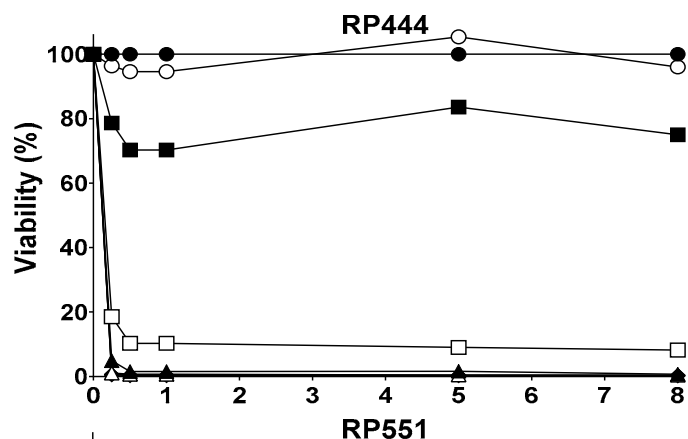

\section{dAMP Concentration}

- $0 \mu \mathrm{g} / \mathrm{mL}$

○ $8 \mu \mathrm{g} / \mathrm{mL}$

- $16 \mu \mathrm{g} / \mathrm{mL}$

$\square 32 \mu \mathrm{g} / \mathrm{mL}$

$\Delta 64 \mu \mathrm{g} / \mathrm{mL}$

$\triangle 128 \mu \mathrm{g} / \mathrm{mL}$

$\checkmark 256 \mu \mathrm{g} / \mathrm{mL}$

$\diamond 512 \mu \mathrm{g} / \mathrm{mL}$
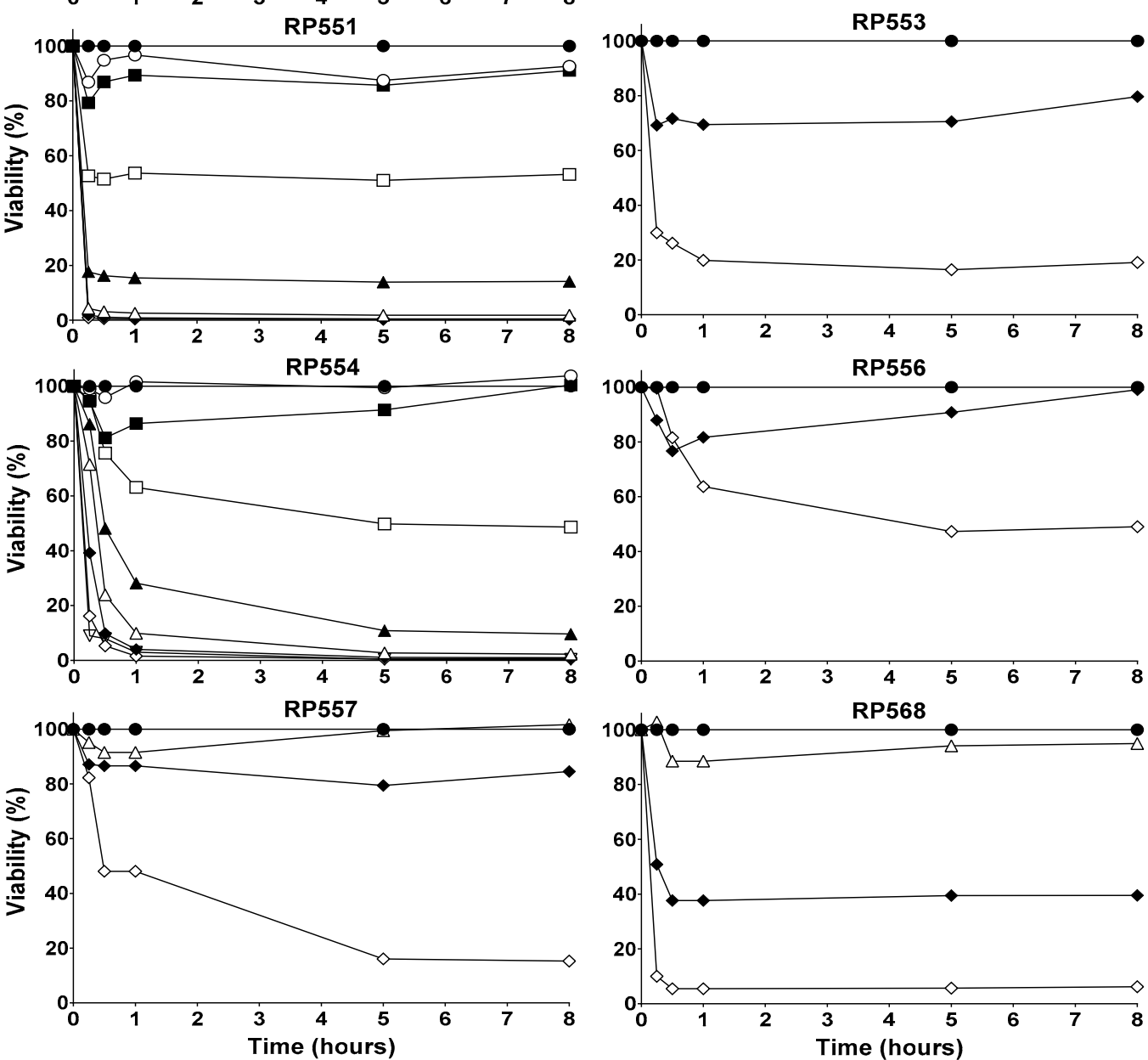

Figure 2. dAMPs, RP553, RP556, RP557 \& RP568, exhibit minimal eukaryotic toxicity. Temporal and dose-response curves of human keratinocyte cytotoxicity through $8 \mathrm{~h}$. Cells were plated at $1 \times 10^{4}$ cells/well, allowed to adhere overnight, the specific dAMP was added, and cytotoxicity evaluated through $8 \mathrm{~h}$. Cellular toxicity was noninvasively assayed using a bioluminescent strain of human keratinocytes and viability assayed using an IVIS Lumina imaging system (Perkin Elmer). Data shown represent the mean of triplicate replicates. 
Table 2. dAMP Therapeutic Index Evaluation.

\begin{tabular}{cccccc}
\hline dAMP & MIC $(\mu \mathrm{g} / \mathbf{m L})$ & $\mathrm{EC}_{\mathbf{1 0}}(\boldsymbol{\mu g} / \mathbf{m L})$ & $\begin{array}{c}\text { Therapeutic } \\
\text { Index }\end{array}$ & EC $_{\mathbf{5 0}}(\boldsymbol{\mu g} / \mathbf{m L})$ & $\begin{array}{c}\text { Therapeutic } \\
\text { Index }\end{array}$ \\
\hline RP444 & 8 & 13 & 1.63 & 20 & 2.5 \\
RP551 & 2 & 16.6 & 8.3 & 34.3 & 17.2 \\
RP553 & 16 & 238 & 39.7 & 268 & 16.8 \\
RP554 & 8 & 19 & 2.38 & 31 & 3.88 \\
RP556 & 4 & 276 & 70 & 519 & 130 \\
RP557 & 8 & 246 & 30.8 & 281 & 35.1 \\
RP568 & $>32$ & 146 & 4.56 & 229 & 7.16 \\
\hline
\end{tabular}

MIC values against the HL043PA2 multi-drug resistant $C$. acnes strain. $\mathrm{EC}_{10}$ and $\mathrm{EC}_{50}$ values were determined using the GraphPad Prism 7 program.

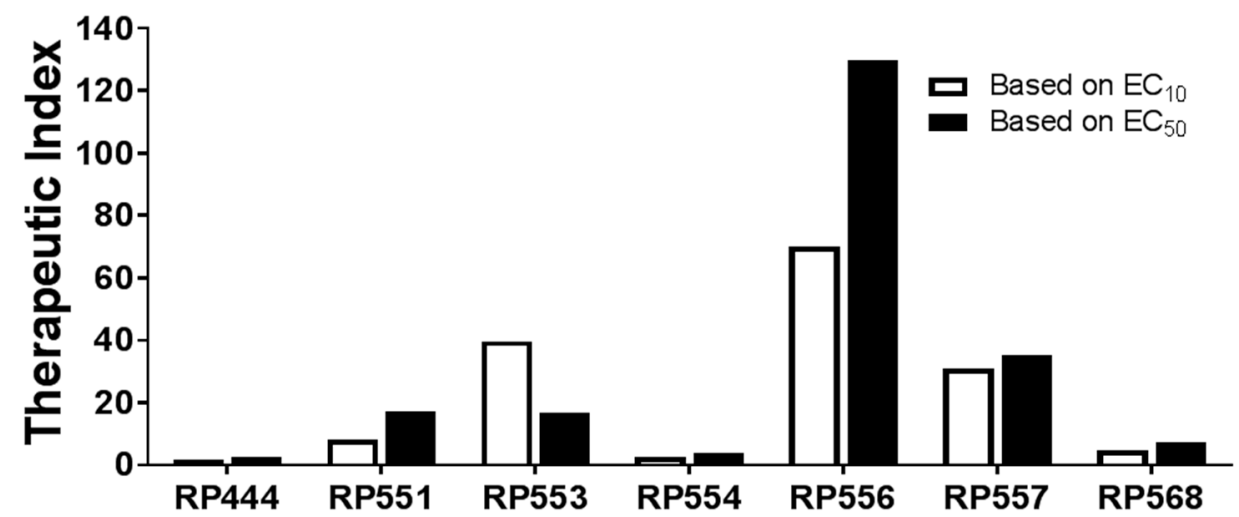

Figure 3. RP556, RP557 and RP553 possess potent selectivity for C. acnes compared to human keratinocytes. dAMP Therapeutic Index evaluation defined by the dose required to kill $10 \%\left(\mathrm{EC}_{10}\right)$ and $50 \%\left(\mathrm{E}_{\mathrm{C} 50}\right)$ of human keratinocytes compared to the C. acnes minimal inhibition concentration (MIC).

RP556 displayed the highest Therapeutic Index with ratios of 130 and 70 for $\mathrm{EC}_{10}$ and $\mathrm{EC}_{50}$, respectively. RP557 and RP553 yielded similar ratios with values of 35 and 16.8, respectively for $\mathrm{EC}_{50}$ evaluations. RP444, RP554, and RP568 yielded the lowest cell selectivity ratios with $\mathrm{EC}_{50}$ index values of $2.5,3.88$, and 7.16 , respectively.

\subsection{RP556 Activity in a Multidrug Resistant C. acnes Murine Model}

A multidrug resistant dermal murine model was developed to evaluate the effectiveness of the lead dAMP, RP556. HL043PA2 is resistant against clindamycin, tetracycline and erythromycin [14]. At $96 \mathrm{~h}$ post-infection, untreated mice demonstrated a mean bacterial burden of $6 \log 10 \mathrm{CFU} / \mathrm{g}$ (Figure 4). There were no untoward clinical observations or changes in body weight following treatment. All mice topically treated with $25 \mu \mathrm{L}$ applications of RP556 (both 5 and $20 \mathrm{mg} / \mathrm{mL}$ ) had mean bacterial burdens below the detectable limit, representing statistically significant decreases compared to both untreated and clindamycin-treated animals. 


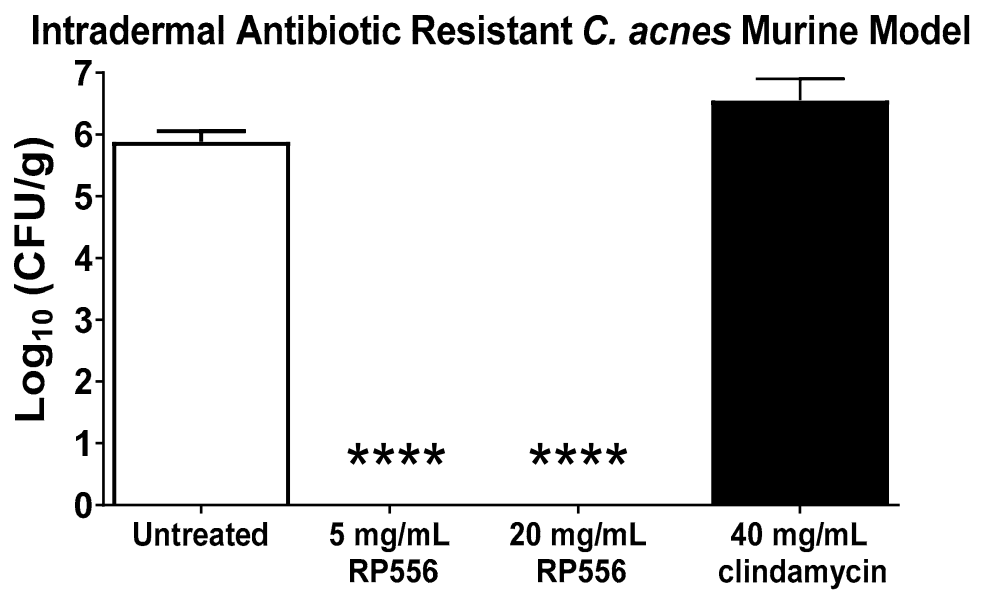

Figure 4. RP556 eradicates C. acnes infection. RP556 (5 or $20 \mathrm{mg} / \mathrm{mL}$ ) or $40 \mathrm{mg} / \mathrm{mL}$ clindamycin was applied topically (using a volume of $25 \mu \mathrm{L}$ ) 2, 14, 26, 38, 50, 62 and $74 \mathrm{~h}$ post infection for a total of 7 applications to BALB/c mice infected with antibiotic-resistant C. acnes. Skin was harvested at $96 \mathrm{~h}$ for bacterial CFU/gram of skin tissue. Each data point represents the mean $\pm \mathrm{SE}$ of six measurements while clindamycin treatment represents four data points. RP556 at 5 and $20 \mathrm{mg} / \mathrm{mL}$ are statistically significant compared to both untreated and clindamycin treated animals $(* * * *, p<0.0001)$ using a one-way ANOVA followed by a Dunnett's post hoc comparison test.

\section{Discussion}

Acne vulgaris is a common skin disorder prevalent among adolescents and young adults [5]. Acne vulgaris can have a profound cutaneous and psychologic disease burden, leading to anxiety, low self-esteem and depression. Significant antibiotic resistance and multiple drug resistance have been observed for $C$. acnes strains from acne patients following long-term antibiotic treatments [1]. The increase in antibiotic resistant $C$. acnes infections has generated an urgent need for new antibacterial agents with novel modes of action and an inherent limited likelihood of developing resistance.

Designed antimicrobial peptides (dAMPs) are engineered analogs of naturally occurring AMPs, which are ubiquitous in nature and provide the first line of defense against invading pathogens. Seven novel dAMPs were synthesized and evaluated for activity against ten antibiotic resistant $C$. acnes and two ATTC reference strains. Five dAMPs (RP444, RP551, RP554, RP556 and RP557) exhibited potent activity against all C. acnes isolates with MIC values of $2-8 \mu \mathrm{g} / \mathrm{mL}$.

An efficacious antimicrobial must be able to selectively inhibit and kill bacteria. The development of a clinically viable dAMP has been hampered by unwanted toxicity to mammalian host cells at therapeutic doses [15]. Therefore, the cytotoxicity of dAMPs was evaluated in human keratinocytes. The in vitro cytotoxicity of dAMPs on human keratinocytes was determined using a newly developed bioluminescence assay. At doses of dAMPs that kill C. acnes upon contact, limited toxicity to eukaryotic cells after $8 \mathrm{~h}$ of exposure was observed, especially with RP553, RP556 and RP557, all of which showed at least greater than $80 \%$ viability following $8 \mathrm{~h}$ incubation at $256 \mu \mathrm{g} / \mathrm{mL}$.

The Therapeutic Index, defined as the concentration at which the dAMP is active against the prokaryotic $C$. acnes pathogen without inducing cytotoxic damage (evaluated using both $\mathrm{EC}_{10}$ and $\mathrm{EC}_{50}$ ) to the surrounding mammalian cells, was evaluated to determine the clinical utility of the candidate dAMPs. RP556 and RP557 demonstrated the largest therapeutic indices with values of 130 and 35.1, respectively. RP556 was then evaluated in vivo, and to ensure the most clinically representative model was utilized, a multidrug-resistant $C$. acnes-induced dermal inflammation model was developed using the HL043PA2 C. acnes strain.

Herein is the identification of a topical anti-infective that will inherently possess fewer adverse effects and drug interactions than systemic agents. RP556 completely eliminated C. acnes infection following a topical application of $5 \mathrm{mg} / \mathrm{mL}$ in a multidrug resistant murine dermal infection 
model. RP556 exhibits potent activity against $C$. acnes antibiotic-resistant strains, possesses a novel mode-of-action with a reduced likelihood of developing bacterial resistance, selectively targets $C$. acnes and not mammalian cells, and eliminates infection in a multidrug-resistant $C$. acnes intradermal murine infection model. If these results are clinically translated, dAMPs (specifically RP556) may serve as a monotherapy for recalcitrant $C$. acnes infection.

\section{Materials and Methods}

\subsection{Designed Antimicrobial Peptides}

Seven dAMPs, whose amino acid sequences are outlined in Table 1, were synthesized via solid phase synthesis (AmbioPharm, North Augusta, SC, USA). Peptide purity was $>96 \%$ as assayed by high performance liquid chromatography and mass spectroscopy.

\subsection{Minimum Inhibitory Concentration (MIC)}

The ten antibiotic resistant $C$. acnes clinical isolates were acquired from BEI resources with the two reference strains obtained from American Type Culture Collection (ATCC, Manassas, VA, USA). C. acnes is a relatively slow-growing, typically aerotolerant anaerobic so all in vitro C. acnes experiments were performed under anaerobic conditions.

Single colonies were inoculated in Reinforced Clostridium Medium (RCM) broth supplemented with sodium thioglycolate and incubated at $37^{\circ} \mathrm{C}$, with shaking at $200 \mathrm{rpm}$, for 2 or 3 days to reach logarithmic growth $\left(\mathrm{OD}_{600 \mathrm{~nm}}=1.0\right)$. Each $C$. acnes $\left(1 \times 10^{6} \mathrm{CFU}\right.$ per $\left.\mathrm{mL}\right)$ was incubated with dAMP or clindamycin at two-fold serial dilutions $(0.5-32 \mu \mathrm{g}$ per $\mathrm{mL})$ in RCM on a 96-well microplate for $48 \mathrm{~h}$. Three replicas were included for each test article concentration. Bacterial growth was measured by optical density at $600 \mathrm{~nm}$ to determine the MIC for each dAMP applied.

\subsection{Mammalian Cytotoxicity}

Noninvasive and real-time monitoring of mammalian cytotoxicity to assess the potential skin toxicity of the dAMPs was evaluated using bioluminescent human immortalized keratinocytes (HaCaT, AddexBio, San Diego, CA, USA). The bioluminescent variant of HaCaT was constructed by transfection with a luciferase gene (RediFect Red-Fluc-Puromycin, Cat\# CL596002) [16]. Keratinocytes $\left(1 \times 10^{4}\right.$ cells, $100 \mu \mathrm{L}$ ) were plated in 96-well black-walled plates. The candidate dAMPs were 2-fold serially diluted from $1024 \mu \mathrm{g} / \mathrm{mL}$ in growth medium supplemented with $150 \mu \mathrm{g} / \mathrm{mL}$ D-luciferin. Each concentration was performed in triplicate, with the final volume being $200 \mu \mathrm{L}$. Imaging was performed at select times $(0,15$, and $30 \mathrm{~min}$ and $1,3,5$, and $8 \mathrm{~h})$ after the addition of the dAMP, and compared to concurrently run vehicle-control, using an IVIS Lumina imaging system (Caliper Life Sciences, Inc., Hopkinton, MA, USA). For imaging, the 96-well plate was positioned on the stage (12.5-cm field of view), with an open emission filter, binning of 4 , and f-stop 1 and a 1-min exposure time. Data analysis was performed using the Living Image software program (version 4.3, Caliper Life Sciences, Inc.). The dAMP concentrations required to kill 10\% and 50\% of keratinocytes were determined using GraphPad Prism 7 (GraphPad Software, San Diego, CA, USA).

\subsection{Animals}

All animals received care in compliance with the Guide for the Care and Use of Laboratory Animals (8th Edition, National Institutes of Health Publication, 2011). All studies were approved by the Institutional Animal Care and Use Committee. Female BALB/c mice, 5 to 7 weeks, were obtained from Envigo Laboratories Inc (Indianapolis, IN, USA). General anesthesia consisted of an intraperitoneal injection of ketamine $100 \mathrm{mg} / \mathrm{kg}$ and xylazine $10 \mathrm{mg} / \mathrm{kg}$ (Vedco, Inc., St. Joseph, MO, USA). 


\subsection{In Vivo Efficacy Assessment of RP556 against Multidrug-Resistant HL043PA2 C. acnes}

Mice were inoculated via intradermal (ID) injection of the antibiotic-resistant C. acnes HL043PA2 (7.0 $\log 10$ CFU, $50 \mu \mathrm{L}$, BEI Resources, HM-514, [14]). The day prior to infection, each mouse was anesthetized using isoflurane, and an area of approximately $1^{\prime \prime} \times 1$ " of skin on the dorsal area of each mouse was shaved and cleared of hair using the depilatory agent Nair ${ }^{\circledR}$. Beginning $2 \mathrm{~h}$ after infection, mice were anesthetized and RP556, formulated in 2\% hydroxypropyl methylcellulose in water, viscosity 3000-5600 cP, or $40 \mathrm{mg} / \mathrm{mL}$ clindamycin (4\%) was administered topically, at $25 \mu \mathrm{L}$ twice daily for a total of 7 applications $(2,14,26,38,50,62$ and $74 \mathrm{~h}$ post infection). Abscesses were harvested at $96 \mathrm{~h}$ post-challenge (or Day 7 for untreated control) and assessed for bacterial CFU per gram of skin tissue.

\subsection{Statistical Analysis}

Quantitative data were expressed as mean \pm standard error of the mean. Statistical analysis was performed using GraphPad Prism 7 (GraphPad Software, San Diego, CA, USA). Comparisons were performed using a 1-way analysis of variance (ANOVA) followed by a post hoc Dunnett's test. A $p$ value $<0.05$ was considered statistically significant.

Author Contributions: Conceptualization, J.J. and K.W.W.; methodology, K.W.W. and L.E.C.; formal analysis, K.W.W. and L.E.C.; investigation, K.W.W. and L.E.C.; writing-original draft preparation, K.W.W.; writing-review and editing, J.J., K.W.W. and L.E.C.; funding acquisition, K.W.W. and L.E.C. All authors have read and agreed to the published version of the manuscript.

Funding: This research was funded by SBIR Phase I grant 1R43AR073036-01.

Conflicts of Interest: All authors own stock in Riptide Bioscience, Inc.

\section{References}

1. Walsh, T.R.; Efthimiou, J.; Dréno, B. Systematic review of antibiotic resistance in acne: An increasing topical and oral threat. Lancet Infect. Dis. 2016, 16, e23-e33. [CrossRef]

2. Tanghetti, E.A.; Popp, K.F. A current review of topical benzoyl peroxide: New perspectives on formulation and utilization. Dermatol. Clin. 2009, 27, 17-24. [CrossRef] [PubMed]

3. Layton, A.M.; Dreno, B.; Gollnick, H.P.; Zouboulis, C.C. A review of the European Directive for prescribing systemic isotretinoin for acne vulgaris. J. Eur. Acad. Dermatol. Venereol. 2006, 20, 773-776. [CrossRef] [PubMed]

4. James, K.A.; Burkhart, C.N.; Morrell, D.S. Emerging drugs for acne. Expert Opin. Emerg. Drugs 2009, 14, 649-659. [CrossRef] [PubMed]

5. Zaenglein, A.L.; Pathy, A.; Schlosser, B.J.; Alikhan, A.; Baldwin, H.E.; Berson, D.S.; Bowe, W.P.; Graber, E.M.; Harper, J.C.; Kang, S.; et al. Guidelines of care for the management of acne vulgaris. J. Am. Acad. Dermatol. 2016, 74, 945-973. [CrossRef] [PubMed]

6. Mills, O., Jr.; Thornsberry, C.; Cardin, C.W.; Smiles, K.A.; Leyden, J.J. Bacterial resistance and therapeutic outcome following three months of topical acne therapy with $2 \%$ erythromycin gel versus its vehicle. Acta Derm. Venereol. 2002, 82, 260-265. [CrossRef] [PubMed]

7. Spellberg, B.; Guidos, R.; Gilbert, D.; Bradley, J.; Boucher, H.W.; Scheld, W.M.; Bartlett, J.G.; Edwards, J., Jr. Infectious Diseases Society of America (2008) The epidemic of antibiotic-resistant infections: A call to action for the medical community from the Infectious Diseases Society of America. Clin. Infect. Dis. 2008, 46, 155-164. [CrossRef] [PubMed]

8. Clemens, L.E.; Jaynes, J.; Lim, E.; Kolar, S.S.; Reins, R.Y.; Baidouri, H.; Hanlon, S.; McDermott, A.M.; Woodburn, K.W. Designed host defense peptides for the treatment of bacterial keratitis. Investig. Ophthalmol. Vis. Sci. 2017, 58, 6273-6281. [CrossRef] [PubMed]

9. Woodburn, K.W.; Jaynes, J.M.; Clemens, L.E. Evaluation of the antimicrobial peptide, RP557, for the broad-spectrum treatment of wound pathogens and biofilm. Front. Microbiol. 2019, 10, 1688. [CrossRef] [PubMed] 
10. Woodburn, K.W.; Clemens, L.E.; Jaynes, J.; Joubert, L.M.; Botha, A.; Nazik, H.; Stevens, D.A. Designed antimicrobial peptides for recurrent vulvovaginal candidiasis treatment. Antimicrob. Agents Chemother. 2019, 63, e02690-18, Print 2019 Nov. [CrossRef] [PubMed]

11. Gordon, Y.J.; Romanowski, E.G.; McDermott, A.M. A review of antimicrobial peptides and their therapeutic potential as anti-infective drugs. Curr. Eye Res. 2005, 30, 505-515. [CrossRef] [PubMed]

12. Berthold, N.; Czihal, P.; Fritsche, S.; Sauer, U.; Schiffer, G.; Knappe, D.; Alber, G.; Hoffmann, R. Novel apidaecin $1 \mathrm{~b}$ analogs with superior serum stabilities for treatment of infections by gram-negative pathogens. Antimicrob. Agents Chemother. 2013, 57, 402-409. [CrossRef] [PubMed]

13. Heyden, M.; Freites, J.A.; Ulmschneider, M.B.; White, S.H.; Tobias, D.J. Assembley and stability of $\alpha$-helical membrane proteins. Soft Matter 2012, 8, 7742. [CrossRef] [PubMed]

14. McDowell, A.; Barnard, E.; Nagy, I.; Gao, A.; Tomida, S.; Li, H.; Eady, A.; Cove, J.; Nord, C.E.; Patrick, S.; et al. An expanded multilocus sequence typing scheme for Propionibacterium acnes: Investigation of 'pathogenic', 'commensal' and antibiotic resistant strains. PLOS ONE 2012, 7, e41480. [CrossRef] [PubMed]

15. Mannis, M.J. The use of antimicrobial peptides in ophthalmology: An experimental study in corneal preservation and the management of bacterial keratitis. Trans. Am. Ophthalmol. Soc. 2002, 100, $243-271$. [PubMed]

16. Hamblin, M.R.; Zahra, T.; Contag, C.H.; McManus, A.T.; Hasan, T. Optical monitoring and treatment of potentially lethal wound infections in vivo. J. Infect. Dis. 2003, 187, 1717-1725. [CrossRef] [PubMed]

(C) 2020 by the authors. Licensee MDPI, Basel, Switzerland. This article is an open access article distributed under the terms and conditions of the Creative Commons Attribution (CC BY) license (http://creativecommons.org/licenses/by/4.0/). 